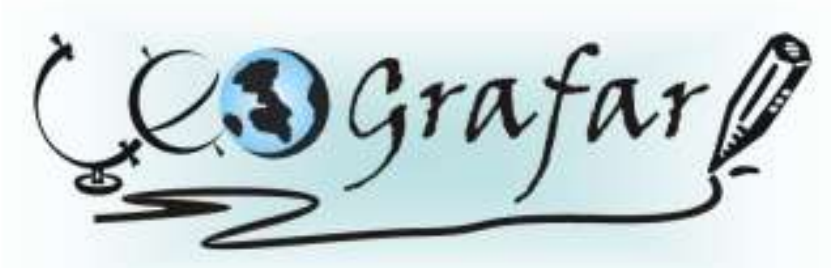

Revista Eletrônica do Programa de Pós-Graduaçāo em Geografla - UFPR

\title{
A CRIAÇÃO DE UNIDADES DE CONSERVAÇÃO COMO INSTRUMENTO DE PROTEÇÃO AOS RECURSOS HÍDRICOS: ESTUDO DE CASO DO PARQUE NASCENTES DO BELÉM - CURITIBA PR
}

\author{
ROSANA ZAFALON ${ }^{1}$ \\ SILVIA KARLA SILVA ${ }^{2}$
}

\begin{abstract}
RESUMO
A degradação dos recursos hídricos é um dos mais graves problemas ambientais a ser enfrentado na atualidade, sobretudo nos países subdesenvolvidos. Rios de grande importância histórica, cultural e econômica "morrem" devido à precariedade do sistema de saneamento básico nas metrópoles brasileiras. Essa é a situação do Rio Belém, que viu nascer e crescer em suas margens a capital paranaense, Curitiba. Programas que visam melhorar a qualidade da água dos rios têm sido implantados, destacando-se a criação de unidades de conservação em pontos estratégicos do curso dos rios, caso da criação, pelo governo municipal, do Parque Nascentes do Belém. No entanto, para que esse projeto seja verdadeiramente eficaz, são necessárias adequações na estrutura física do parque, bem como a promoção, pelo poder público, de programas de educação ambiental, não somente nesse espaço como também em outros, como por exemplo, nas escolas, que possam atingir toda a população curitibana, conscientizando-a da importância da preservação da qualidade da água de seus rios.

Palavras-chave: Educação ambiental. Recursos hídricos. Unidades de conservação. Rio Belém.
\end{abstract}

\footnotetext{
${ }^{1}$ Bacharel em Geografia pela UFPR (2009). Especialista em Educação Ambiental pela FACET (2011). Mestranda em Geografia pela UFPR. E-mail: rosanazafalon@gmail.com.

2 Licenciada em Geografia pela UFPR (2009). Especialista em Educação Ambiental pela FACET (2011).
} 


\title{
THE ESTABLISHMENT OF PROTECTED AREAS AS A TOOLFOR PROTECTION OF WATER RESOURCES: A CASE STUDYOF BETHLEHEM PARK SPRINGS
}

\begin{abstract}
The degradation of water resources is one of the most serious environmental problems being faced today, especially in underdeveloped countries. Rivers of great historical, cultural and economic "die" due to poor sanitation system in Brazilian cities. This is the situation in Rio Belém who was born and grows on its banks the capital of Paraná, Curitiba. Programs aimed at improving the water quality of rivers has been implanted, with emphasis on the creation of conservation units in strategic locations of rivers, where the establishment by the municipal government, the Municipal Park of the Springs Belém. However, for this project to be truly effective, it is necessary adaptations in the physical infrastructure of the park as well as the promotion by public authorities, environmental education programs, not only in space but also in others, such as schools, which may reach the entire population Curitiba, a well-aware of the importance of preserving water quality in rivers.
\end{abstract}

KEY WORDS: Environmental education. Water resources. Conservation units. Rio Belém

\section{INTRODUÇÃO}

Nas últimas décadas, como aponta Floriano (2004), a sociedade passou a se questionar a respeito dos resultados de suas ações sobre o meio ambiente, percebendo que os recursos do planeta não são ilimitados e que mesmo considerando o grande potencial de autodepuração da natureza, este também constitui um fator limitado.

De acordo com o autor, essa preocupação, mais forte desde a ECO-92, tem fortalecido a importância do planejamento ambiental. "Percebemos a necessidade de definir até que ponto podemos alterar a biosfera e passamos a ter certeza de que é preciso planejar nossas ações quanto ao que fazemos com relação ao ambiente em que vivemos". (FLORIANO, 2004, p. 5)

Considerando os resultados das atividades antrópicas sobre o meio ambiente, torna-se fundamental criar mecanismos que minimizem os impactos humanos, principalmente quando essas ações afetam a qualidade das águas, recurso essencial à vida. O comprometimento da potabilidade da água, através da contaminação com os mais diversos agentes poluidores, sobretudo os dejetos 
industriais e domésticos, pode resultar em graves problemas de saúde, tanto às pessoas quanto aos animais. (FLORIANO, 2004)

Carvalho e Rodrigues (2004) afirmam que a água é um recurso natural renovável, porém exaurível, e que tem sido impactada por ações socioeconômicas, causando assim sua degradação, processo esse que a cada dia se torna mais acelerado. Desse modo, de acordo com os autores, o gerenciamento da água também implica no gerenciamento de diversos processos ambientais e no planejamento do espaço territorial, para que assim os parâmetros de sustentabilidade ambiental dos sistemas naturais remanescentes sejam respeitados.

Para Carvalho e Rodrigues (2004) as últimas décadas foram marcadas pelo aumento da pressão social sobre os recursos naturais, e no que confere aos recursos hídricos podem ser apontados como fatores responsáveis pelo aumento de demanda o crescimento demográfico e ao aumento da diversificação dos usos da água.

Os rios urbanos, por sua vez, são os que mais têm sofrido com essa pressão social, e nesse contexto, se sobressai a importância das unidades de conservação para a manutenção da qualidade da água dos mananciais.

Autores como Rylands e Brandon (2005) apontam que os estudos sobre a relevância das unidades de conservação vêm ganhando importância nos últimos anos, visto que, apesar de os primeiros parques brasileiros terem sido estabelecidos em 1937, foi só nas últimas duas décadas que houve uma explosão no número de tais unidades no Brasil.

É nesse contexto que, em 2001, foi criado o Parque Nascentes do Belém, no município de Curitiba. O objetivo da criação do parque, segundo o poder público, é a proteção da área que abriga o nascedouro do Belém, principal rio que corta a capital paranaense.

Desse modo, o presente artigo tem por objetivo investigar se a implantação do Parque Nascentes do Belém tem contribuído com a proteção ambiental da nascente do Rio Belém e ao mesmo tempo dado suporte para a prática de atividades de educação ambiental nesse espaço.

Em razão das dificuldades de se coletar dados primários, essa pesquisa baseou-se, sobretudo na análise de documentos, constituindo-se dessa forma, numa pesquisa documental. Para Sá-Silva et al. (2009, p. 5), "a pesquisa documental é um 
procedimento que se utiliza de métodos e técnicas para a apreensão, compreensão e análise de documentos dos mais variados tipos". De acordo com os autores, é muito importante que ocorra uma valorização do uso de documentos em pesquisa, afinal, a partir deles é possível levantar uma grande riqueza de informações, justificando desse modo, a sua adoção em diversas áreas das Ciências Humanas e Sociais, pois "possibilita ampliar o entendimento de objetos cuja compreensão necessita de contextualização histórica e sociocultural". (SÁ-SILVA et al., 2009, p. 2)

Também compõe a metodologia do presente trabalho, a coleta de dados secundários junto ao departamento municipal do meio ambiente e demais órgãos ambientais e ainda dados primários sobre a caracterização e funcionamento atual do objeto investigado obtidos através de visita ao Parque Nascentes do Belém.

\section{A DEGRADAÇÃO DOS RECURSOS HÍDRICOS NO BRASIL}

A relação homem e meio ambiente vem sendo abordada, sobretudo nas últimas décadas, sob a dimensão dos impactos antrópicos ao meio natural. (MORAES e JORDÃO, 2002).

Para Moraes e Jordão (2002) é possível classificar os impactos exercidos pelo homem sobre o meio ambiente em dois tipos. O primeiro trata do consumo de recursos naturais em ritmo mais acelerado do que aquele no qual eles podem ser renovados pelo sistema ecológico e o segundo da geração de produtos residuais em quantidades maiores do que as que podem ser integradas ao ciclo natural de nutrientes.

A respeito desse tema, Salati et al. (2006), traçam uma previsão para os problemas ambientais mais relevantes que o Brasil deve enfrentar nos próximos anos e, é claro, a degradação dos recursos hídricos aparece como um sério desafio para o futuro próximo.

Moraes e Jordão (2002, p. 372) ressaltam também a posição privilegiada do Brasil no mundo em relação aos recursos hídricos, pois em relação ao demais, nosso país "detém $8 \%$ de toda a reserva de água, sendo que $80 \%$ da água doce do país encontram-se na região Amazônica, ficando os restantes $20 \%$ circunscritos ao abastecimento das áreas do território brasileiro onde se concentram 95\% da população". 
Para Rebouças (2003) há um discurso que ressalta a generosa oferta de recursos hídricos do Brasil, sua vasta rede de drenagem, o que acaba engendrando a ideia de abundância de água em nosso país, que por sua vez, passa a soar contraditório quando lembramos que muitas cidades brasileiras enfrentam crises de abastecimento.

Desse modo, considerando a disponibilidade hídrica do nosso país, com grandes reservas superficiais e subterrâneas de água doce, poderíamos pensar que o Brasil não enfrenta dificuldades hídricas. No entanto, é preciso considerar, como ressaltam Barros e Amin (2008), que a distribuição da água doce em nosso país é irregular, concentrando-se na Região Norte, área pouco habitada em relação às demais regiões do país, o que, somado aos problemas de contaminação dos recursos hídricos, sobretudo em áreas urbanas, pode conduzir à escassez e acarretar sérios problemas de abastecimento.

Barros e Amin (2008, p. 99) também afirmam que a abundância da água, aliada à grande dimensão do Brasil, "favorece o desenvolvimento de uma consciência de inesgotabilidade, isto é, a um consumo distante dos princípios de sustentabilidade e sem preocupação com a escassez."

Por isso, Rebouças (2002) afirma que a deterioração dos recursos hídricos pela ação antrópica pode gerar uma crise hídrica mesmo nos países com grande disponibilidade de água, como por exemplo, no Brasil.

A precariedade do abastecimento de água e da coleta e tratamento de esgoto no Brasil são alarmantes e em muito tem contribuído para a degradação dos recursos hídricos.

De acordo com a Pesquisa Nacional de Saneamento Básico 2008 do IBGE, é muito preocupante a situação do esgotamento sanitário no Brasil, pois verifica-se a falta de rede coletora de esgoto em 2.495 municípios, distribuídos pelas Unidades da Federação, com exceção do Estado de São Paulo, onde apenas uma cidade não apresentava o serviço de esgotamento através de rede coletora. (IBGE, 2010; 2011)

A PNSB 2008 também mostra que pouco mais da metade dos municípios brasileiros $(55,2 \%)$ tinham serviço de esgotamento sanitário por rede coletora, que é o sistema apropriado, marca pouco superior à observada na pesquisa anterior, realizada em 2000, que registrava 52,2\%. Em 2008, a proporção de municípios com rede de coleta de esgoto foi bem inferior à de municípios com rede geral de 
distribuição de água (99,4\%), manejo de resíduos sólidos (100,0\%) e manejos de águas pluviais (94,5\%). (IBGE, 2010; 2011)

Verificou-se assim um aumento na proporção de domicílios com acesso à rede de esgoto que passaram de $33,5 \%$, em 2000 , para $45,7 \%$, em 2008 . No entanto, quando observamos esses dados regionalmente verifica-se que apenas na Região Sudeste mais da metade dos domicílios (69,8\%) tinham acesso à rede geral. A segunda região em cobertura do serviço foi a Centro-Oeste (33,7\%), com resultado próximo ao da Região Sul $(30,2 \%)$. Seguem-se as Regiões Nordeste $(29,1 \%)$ e Norte $(3,5 \%)$. (IBGE, 2010; 2011)

Analisando ainda as unidades da federação, constatou-se que os únicos estados com mais da metade dos domicílios atendidos por rede geral coletora de esgoto foram: Distrito Federal (86,3\%); São Paulo (82,1\%); e Minas Gerais (68,9\%). O Rio de Janeiro $(49,2 \%)$ e o Paraná $(46,3 \%) \%)$, com quase metade dos domicílios atendidos, se situaram acima da média nacional (44,0\%), enquanto os demais apresentaram menos de $35 \%$ de cobertura, ficando as menores proporções com os Estados do Amapá (3,5\%), Pará (1,7\%) e Rondônia (1,6\%). (IBGE, 2010; 2011)

Quando observamos as regiões de acordo com a presença de municípios que contam com rede coletora de esgoto, a Região Sudeste também aparece bem mais a frente que as demais, contanto com esse atendimento em 95,1\% dos municípios. Desse modo, em 2008, em todas as demais regiões do Brasil, menos da metade dos municípios apresentavam rede coletora de esgoto, sendo a maior proporção observada na Região Nordeste $(45,7 \%)$, seguida pelas Regiões Sul $(39,7 \%)$, Centro-Oeste $(28,3 \%)$ e Norte $(13,4 \%)$. E ainda, das 26 Unidades da Federação (sem considerar o DF), em apenas oito, mais da metade dos municípios possuíam rede coletora de esgoto, sendo os extremos representados pelos Estados de São Paulo (99,8\%) e Piauí (4,5\%). (IBGE, 2010; 2011)

É importante ressaltar que a estatística de acesso à rede coletora de esgoto refere-se apenas à existência do serviço no município, sem considerar a extensão da rede, a qualidade do atendimento, o número de domicílios atendidos, ou se o esgoto, depois de recolhido, é tratado, de modo que esses dados podem camuflar uma realidade ainda mais preocupante. (IBGE, 2010; 2011)

Portanto, considerando a relação proporcional entre o número de municípios com rede de esgotamento sobre o total de municípios de cada Unidade da 
Federação e a distribuição espacial dos municípios com rede de esgotamento sanitário, os dados da PNSB 2008 mostram que, de modo geral, existiu um avanço em termos de proporção de municípios atendidos no período de 1989 a 2008, apesar de esse atendimento ainda se encontrar, na atualidade, muito longe do necessário. (IBGE, 2010; 2011)

Em relação aos avanços alcançados de 2000 a 2008, é preciso considerar um pequeno aumento no número de municípios com rede coletora de esgoto, mas nas Grandes Regiões alguns avanços foram consideráveis. Esse é o caso da Região Norte, onde a proporção quase dobrou no período, passando de 7,1\%, em 2000 , para $13,4 \%$, em 2008. Houve também um aumento significativo na Região Centro-Oeste, de $17,9 \%$ para $28,3 \%$. (IBGE, 2010; 2011)

Apesar de importantes, tais melhoras, pouco impactaram no resultado do Brasil, visto que essas duas regiões respondem por um percentual pequeno do total dos municípios brasileiros. Por sua vez, nas regiões com maior número de municípios - Sudeste e Sul - as melhoras foram pouco significativas, vejamos: No Sudeste, de $92,9 \%$ dos municípios atendidos, em 2000, passaram para 95,1\%, em 2008; no Sul, de 38,9\% para 39,7\%, respectivamente. Na Região Nordeste, também houve pouca variação na cobertura desse serviço, que passou de $42,9 \%$, em 2000 , para 45,7\%, em 2008. (IBGE, 2010; 2011) 


\section{FIGURA 1 - MUNICÍPIOS COM SERVIÇO DE REDE COLETORA DE ESGOTO -}

BRASIL - 2008

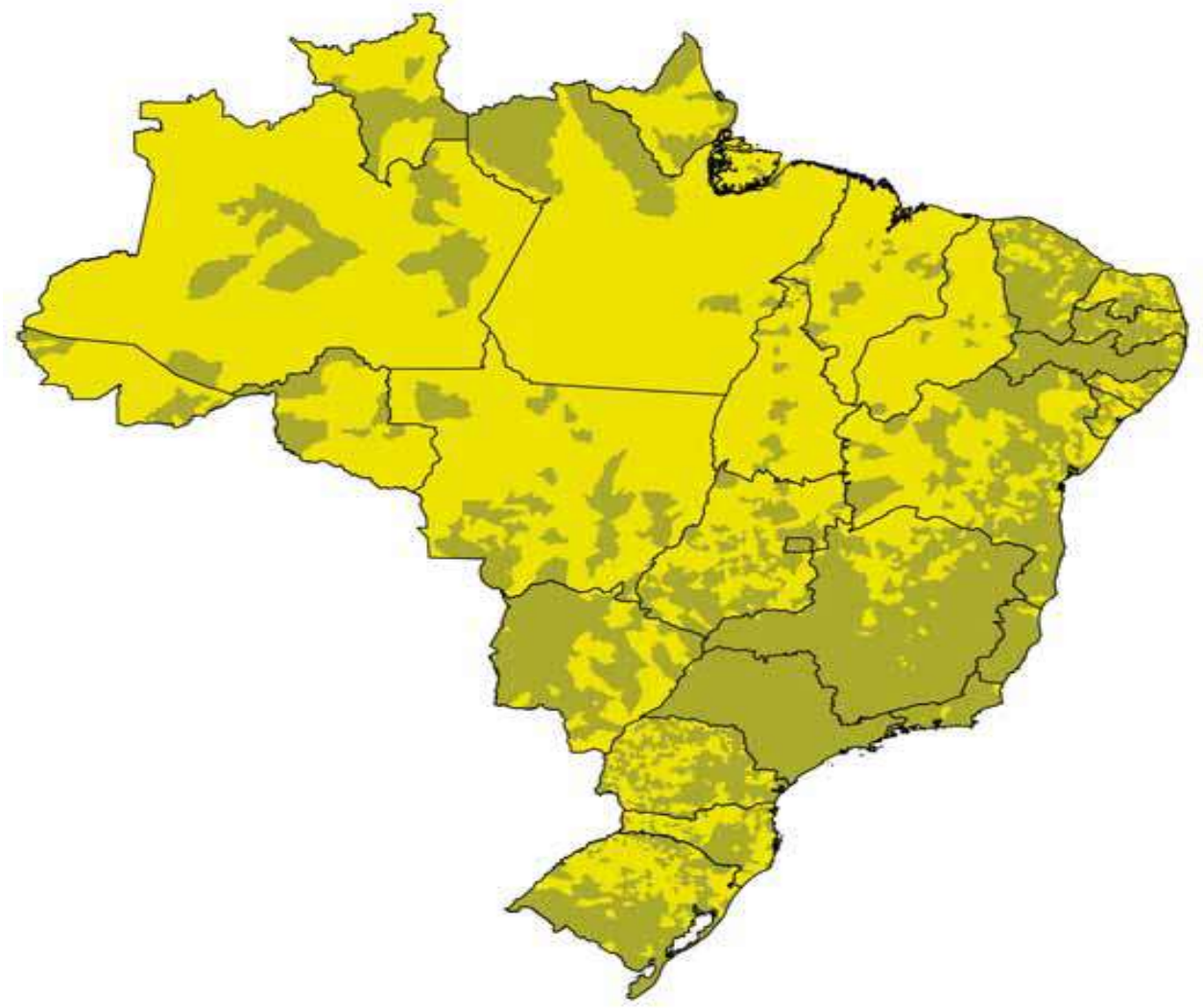

- Municípios com atendimento de rede de esgoto sanitário.

Fonte: IBGE, Diretoria de Pesquisas, Coordenação de População e Indicadores Sociais, Pesquisa Nacional de Saneamento Básico 2008. (IBGE, 2010)

A PNSB 2008 aborda ainda às principais soluções alternativas quando da ausência de redes básicas de saneamento, no caso do abastecimento de água e esgotamento sanitário. No primeiro, a ausência de rede de distribuição de água é compensada por um número variado de alternativas, como chafariz, poço particular, carro-pipa, corpo d'água, cisternas, bica, etc. Nessa pesquisa foi possível identificar 794 municípios no Brasil onde, independentemente da existência de rede geral de abastecimento, ocorreu a distribuição de água por outras formas. Adicionando a esse número os 33 municípios, onde não há rede geral de abastecimento, verificouse que a ocorrência de fornecimento de água por formas alternativas atingiu o patamar de 827 (14,9\%) municípios brasileiros. (IBGE, 2010; 2011)

Já em relação ao esgoto sanitário, as soluções alternativas se referem fossas sépticas e sumidouro, fossa rudimentar, fossa seca, vala a céu aberto e lançamentos em corpos d'água, soluções essas que longe de representarem 
alternativas constituem, antes, a confirmação da precariedade da coleta de esgoto no país. (IBGE, 2010; 2011)

Além dos graves problemas de saneamento básico existem as perdas totais da água tratada e injetada nas redes de distribuição das cidades, que variam de $40 \%$ a $60 \%$ no Brasil, contra $5 \%$ a $15 \%$ nos países desenvolvidos. O consumo de água, por sua vez, também é alto. Em média, o consumo brasileiro é de 200 litros/dia, enquanto a UNESCO admite que uma pessoa necessita de 40 litros/dia. Corroborando com essas informações, Barros e Amin (2008), ressaltam que esse quadro agrava ainda mais o quadro do desperdício no Brasil.

Portanto, ademais da precariedade de saneamento básico, o desperdício na hora do consumo também afeta a disponibilidade hídrica no Brasil. Rebouças (2003) cita como exemplos de desperdício de água os banhos prolongados, o hábito de lavar calçadas, pátios e carros com jatos de mangueiras, uso de bacias sanitárias que necessitam de 18 litros a 20 litros de água por descarga ao invés de equipamentos mais modernos (que requerem de 3 a 6 litros), irrigação de gramados públicos e privados com água tratada, entre outras práticas. Isso, é claro, sem falar no desperdício de água na agricultura por causa de métodos e técnicas de irrigação obsoletas, atividade que, de acordo com Rebouças (2003), tanto no Brasil quanto em nos demais países, é responsável pelo consumo de quase $63 \%$ da demanda de água.

Salati et al. (2006) apontam as principais fontes de contaminação dos recursos hídricos no Brasil, dando destaque para a contaminação por efluentes nas áreas urbanas.

\footnotetext{
As águas superficiais nas proximidades dos centros urbanos encontram-se quase sempre poluídas por fontes pontuais de efluentes domésticos ou industriais, ou pela poluição difusa, oriunda de atividades agrícolas e agropecuárias. A escassez de água em algumas regiões poderá tornar-se crítica pelo crescimento do consumo de água para atividades industriais e irrigação (SALATI et al., 2006, p. 109).
}

Tundisi (2005, p.689) aponta a integração entre pesquisa e gestão como ferramenta essencial ao gerenciamento adequado dos recursos hídricos no Brasil, essa medida se justifica, pois, segundo o autor, a população brasileira ainda sofre com doenças de veiculação hídrica, e desse modo, é fundamental a implantação de políticas de saneamento básico que tenham por objetivo a "recuperação de 
mananciais, a distribuição de água adequada para a população e ainda medidas de segurança coletiva para erradicar epidemias devido à má qualidade da água".

Barros e Amin (2008) ressaltam que, embora o Brasil disponha de uma legislação considerada avançada para os recursos hídricos, ainda são poucos os resultados práticos de sua aplicação, o que, aliado à ideia de inesgotabilidade desse recurso no país, a oferta gratuita de água, pois a cobrança existente só cobre os custos de administração do recurso e não seu valor econômico, e a crença de sua capacidade ilimitada de recuperação, gera uma postura descomprometida com a proteção e o equilíbrio ecológico. Para os autores, é preciso implantar no Brasil um modelo de gestão dos recursos hídricos que considere a água como um bem econômico que a cada dia torna-se mais valorado, criando também mecanismos que promovam a cobrança pelo uso dos recursos hídricos e torne a água uma commodity a ser exportada, contribuindo para o desenvolvimento do país.

Barros e Amin (2008) destacam que, no Brasil, a ANA (Agência Nacional de Águas) tem promovido estudos, mecanismos e formas de monitoramento para gerenciar os recursos hídricos, mas mesmo assim, a água continua sendo encarada como um bem gratuito e infinito. É por isso que, segundo os autores, a degradação, ocasionada pelo mau uso, é intensa, gerando um consumo predatório e ineficiente, pois a população não se preocupa com a possibilidade de escassez e nem com as formas adequadas de uso da água.

Sendo essa a realidade do país, Barros e Amin (2008) apontam duas frentes de ação: a primeira seria tornar a água um bem econômico, sendo assim administrada, controlada e taxada de acordo com o valor que os recursos verdadeiramente têm; a segunda frente seriam investimentos em educação ambiental, "pois essa deverá agir de forma a conscientizar a opinião pública sobre o tema, demonstrando as reais necessidades da utilização da água potável, a dificuldade de obtenção e a necessidade de mantê-la adequada ao consumo humano." (BARROS e AMIN, 2008, p. 102)

Vale ainda ressaltar que políticas de proteção e monitoramento dos recursos hídricos, aliadas a investimentos em saneamento também são essenciais por parte dos estados, pois Libânio (2005, p. 226) constatou que "o bem-estar das populações é melhor retratado pela abrangência dos serviços de água e de esgotamento sanitário, do que propriamente pelo potencial hídrico ou pela disponibilidade de água 
per capita". Essa conclusão ressalta a importância do setor de saneamento para a proteção dos recursos hídricos e à promoção da saúde pública. Para esse autor, "o sistema de gestão de águas a ser implementado no Brasil somente garantirá o aproveitamento sustentável desse recurso se for estabelecida uma nova dinâmica para o planejamento e para a realização de ações de saneamento". (LIBÂNIO, 2008, p.227)

Mas de nada adianta o avanço na legislação se a população não for alvo de campanhas de conscientização ambiental. Hoje, mais do que nunca, as pessoas precisam compreender a dimensão dos impactos de suas ações sobre o meio em que vivem. Neste contexto, surgem as Unidades de Conservação como instrumentos de proteção aos recursos naturais, mas que também devem ser utilizadas na promoção da educação ambiental, visando desse modo, uma convivência sustentável entre o homem e a natureza.

\section{UNIDADES DE CONSERVAÇÃO (UCS) E A PROTEÇÃO DOS RECURSOS HÍDRICOS}

A criação de áreas protegidas aconteceu primeiramente nos Estados Unidos com o objetivo de proteger a vida selvagem ameaçada pela civilização urbanoindustrial destruidora da natureza (SILVA, 2004). O precursor desse processo foi o Parque Nacional de Yellowstone em 1872 (RUNTE, 1979 apud SILVA, 2004). Até 1999 já havia mais de dez mil unidades de conservação em 150 países.

De acordo com a União Internacional para a Conservação da Natureza (UICN, 2011) a definição para áreas protegidas é "uma área terrestre ou marinha dedicada especialmente à proteção e à manutenção da diversidade biológica e dos recursos naturais e culturais associados, gerida por meios efetivos legais ou de outro tipo mais eficazes".

No Brasil, segundo Pádua (1997) apud Silva (2004), o engenheiro André Rebouças, no ano de 1876 sugeriu a criação de dois Parques Nacionais: O Parque Nacional na llha do Bananal (Tocantins) e outro na região das Sete Quedas. Porém a primeira unidade de conservação dessa categoria foi criada no estado de São Paulo em 1886 e a primeira unidade de conservação nacional foi o Parque Nacional do Itatiaia no Rio de Janeiro, em 1937. 
Até a década de 1970 não havia critérios para a criação de unidades de conservação, as áreas eram escolhidas por critérios paisagísticos e políticos. Somente a partir de 1970 critérios científicos começaram a ser utilizados. (PADUA, 1997 apud SANTOS JUNIOR, 2006)

Ainda segundo Pádua, a partir da década de 1980, houve um crescimento acelerado na criação das unidades de conservação, com a criação dos Parques de Abrolhos, na Bahia e Fernando de Noronha, em Pernambuco. (SANTOS JUNIOR, 2006)

No entanto, é somente a partir da década de 1990 que a preservação da biodiversidade passa a ter grande importância na criação das unidades de conservação. Começa a aparecer o termo desenvolvimento sustentável, o que pode ser notado através da criação de Reservas Extrativistas e Reservas particulares do Patrimônio Natural. (COSTA, 2002)

A Lei Federal de número 9985 de 18 de julho de 2000, que regulamenta o artigo 225, § 1ำ, incisos I, II, III e VII da Constituição Federal, institui o Sistema Nacional de Unidades de Conservação da Natureza e outras propriedades (SNUC), estabelecendo critérios para a criação e gestão das Unidades de Conservação.

No artigo $2^{\circ}$, inciso I, temos as definições de Unidades de Conservação, assim descrito como: "o espaço territorial e seus recursos ambientais, incluindo as águas jurisdicionais, com características naturais relevantes, legalmente instituído pelo Poder Público, com objetivos de conservação e limites definidos, sob regime especial de administração, ao qual se aplicam garantias adequadas de proteção".

A identificação de áreas vulneráveis e que precisam ser transformadas em Unidades de Conservação, faz-se através de um zoneamento urbano. Podemos definir o zoneamento como um instrumento de política urbana (Estatuto das Cidades $^{3}$, Lei 10.257/2002). No Zoneamento Ambiental Urbano, faz-se um estudo das potencialidades e dos riscos que as áreas apresentam.

Em relação aos recursos hídricos, Carvalho e Braga (2005) afirmam a importância do estudo e compreensão das transformações da água (solvente universal, modelador de relevos, insumo e vetor de vida e doenças) no meio

\footnotetext{
${ }^{3}$ A lei que regulamenta os artigos da Constituição Federal sobre a política urbana é o Estatuto da Cidade, Lei 10.257/2001, é ela que estabelece as normas a serem aplicadas em todos os municípios no que tange a regularização fundiária, em especial nas áreas de ocupação irregular, a relação Campo X Cidade, a garantia da preservação ambiental, entre outros.
} 
ambiente urbano, desde a sua dinâmica no ciclo hidrológico (radicalmente transformado pelas ações antrópicas, principalmente a urbanização) até a sua qualidade físico-química, de modo a facilitar e viabilizar tanto a gestão ambiental das cidades como os próprios recursos hídricos na perspectiva do desenvolvimento sustentável.

Carvalho \& Braga (2005) ainda ressaltam o objetivo 15 da agenda 21 Brasileira, no que diz respeito a suas ações prioritárias: "fazer a população participar do destino de seus rios mais próximos, adotá-los como um bem a ser protegido". Também na Agenda 21 brasileira, foram apontadas algumas ações e recomendações a respeito da preservação das águas, entre elas cita-se: "promover a educação ambiental, principalmente das crianças e dos jovens nos centros urbanos, quanto às consequências do desperdício de água".

A preocupação com nossos recursos hídricos está cada vez mais presente, uma vez que os grandes centros urbanos estão crescendo e ocupando áreas que deviam ser protegidas. Com base neste pensamento, em Curitiba, foram criados inúmeros parques ao longo dos principais rios que cortam a cidade. Esse interesse pelos recursos hídricos se reflete também no Plano Diretor da cidade.

Com base no artigo 182 da Constituição Federal, o Plano Diretor é obrigatório para cidades com mais de vinte mil habitantes e tem por objetivo ordenar o pleno desenvolvimento das funções sociais da cidade e garantir o bem-estar de seus habitantes (BRASIL, 1988).

De acordo com Meireles, 1996, apud Silva et al (2008), "o Plano Diretor deve respeitar a realidade do Município e fazer planejamentos de médio e longo prazo. Assim, o Plano Diretor consiste em um instrumento para efetivar o desenvolvimento social, urbano, econômico e ambiental da população".

Segundo Silva et al (2008) o Plano Diretor de Curitiba é de 1966, tendo sido revisado em 2004, com base no Estatuto da Cidade. Curitiba possui estrutura administrativa própria para o meio ambiente e também legislação municipal integrada ao Plano Diretor visando a preservação dos recursos naturais.

Porém, o que se constata é que mesmo com uma base institucional estruturada em torno da preservação e do uso adequado do solo através da lei de zoneamento ambiental e de ocupação, a qualidade do meio ambiente não tem sido mantida. Essa situação pode ser exemplificada através da crescente redução da 
qualidade das águas dos rios da Bacia do Iguaçu, responsáveis pelo atendimento da capital paranaense, onde a maioria dos pontos analisados são considerados poluídos. (SILVA et al., 2008)

É preciso lembrar que, de acordo com a Organização das Nações Unidas (ONU), a poluição é o principal motivo da falta de água para quase metade da população mundial para atendimento ao mínimo necessário. (SILVA et al., 2008)

Para BRITO e CÂMARA (1999) apud SILVA (2004), deve-se conciliar a ação antrópica com a preservação ambiental para que se mantenham as funções ecológicas dos ecossistemas. Onde não há proteção do Poder Público, os ecossistemas estão sendo, cada vez mais, deteriorados pelo inadequado uso e ocupação do solo, poluição crescente, desmatamentos frequentes, queimadas, entre outros problemas.

Diante disso, observa-se uma crescente necessidade de, não somente, serem criadas unidades de conservação, como também, de se aplicar a legislação de forma eficiente, levando-se em conta também o entorno dessas unidades, uma vez que a população desse entorno deve conhecer a unidade em questão, sua importância ambiental/natural/cultural, de modo a se evitar ao máximo o impacto antrópico nessas áreas. Essa situação pode ser verificada e observada na prática na bacia hidrográfica do Rio Belém em Curitiba, foco de análise deste estudo.

\section{A BACIA HIDROGRÁFICA DO RIO BELÉM}

Assim como ocorre em muitas cidades no mundo inteiro, também diversas cidades paranaenses apresentam mananciais deteriorados em função da presença de ocupações irregulares e do lançamento de lixo e esgoto sem tratamento prévio nos rios. Na capital do estado, Curitiba, a intensa degradação do rio Belém, rio de grande importância histórica para a cidade, constitui uma prova da degradação hídrica urbana. (BONATTO, 2000)

O processo de urbanização de Curitiba, como na maioria dos municípios do Brasil, ocorreu ao longo de seus rios, e o crescimento urbano acelerado não foi acompanhado de ações eficientes que pudessem manter e preservar a qualidade dos recursos hídricos. (BONATTO, 2000). 
O rio Belém é considerado um rio genuinamente curitibano, pois, conforme é possível observar no mapa abaixo, se encontra totalmente dentro do município de Curitiba, desde sua nascente na região norte da cidade, no Bairro Cachoeira, até sua foz, onde é tributário da margem direita do rio lguaçu, na região sul da cidade, Bairro Boqueirão. (BOLLMANN e EDWIGES, 2008)

A Bacia do Rio Belém possui 84 km² de área de drenagem, o que representa cerca de $20 \%$ da área do município de Curitiba abrigando ainda aproximadamente $50 \%$ de sua população. (BOLLMANN e EDWIGES, 2008)

\section{FIGURA 2 - MAPA DE LOCALIZAÇÃO DA BACIA DO RIO BELÉM}

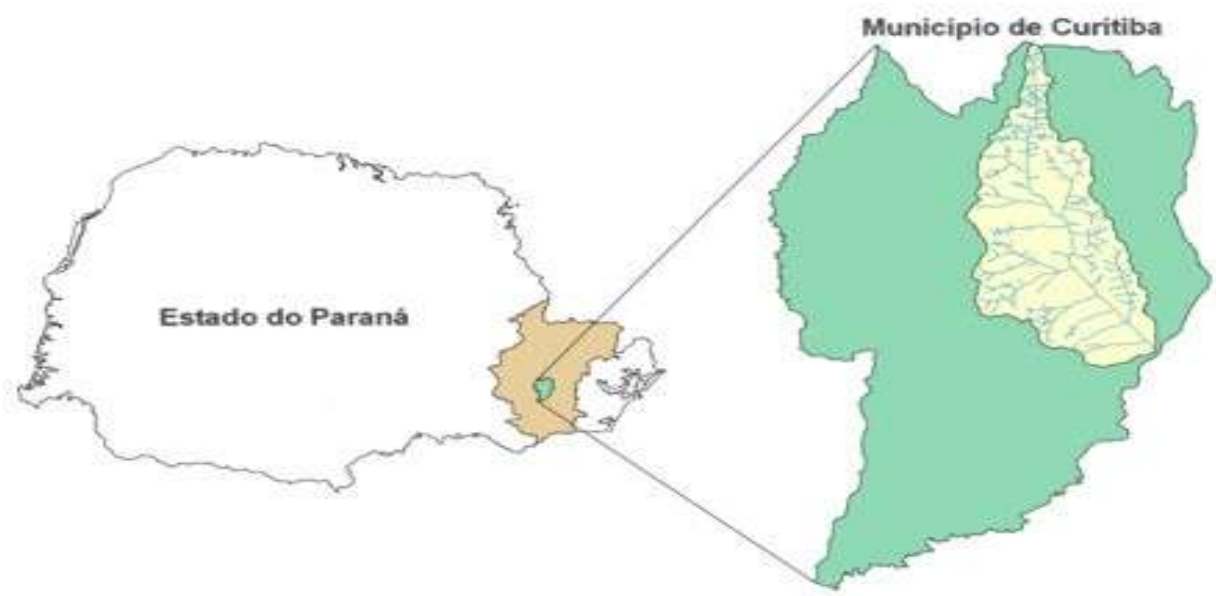

Bacia Hidrográfica do Rio Belém

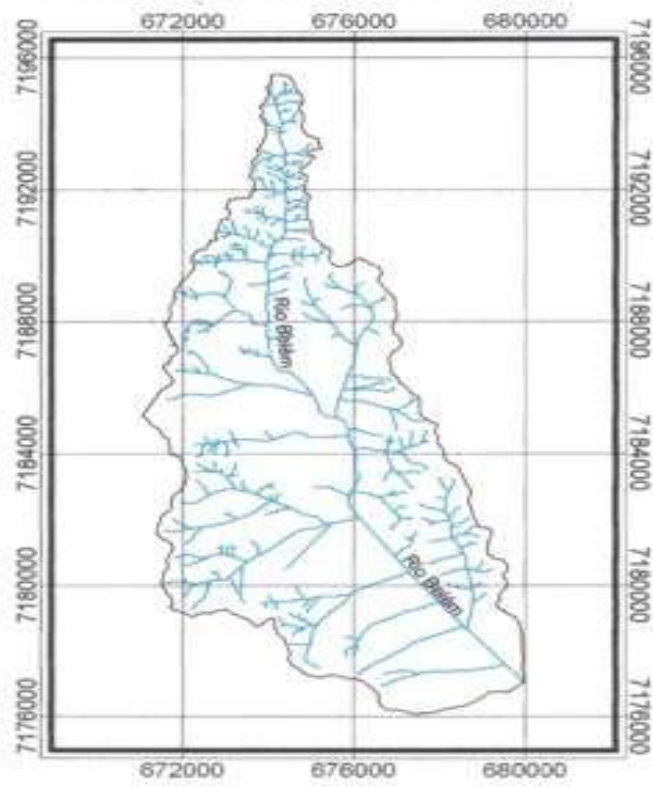

LEGENDA

Hidrografia

Divisor de Água

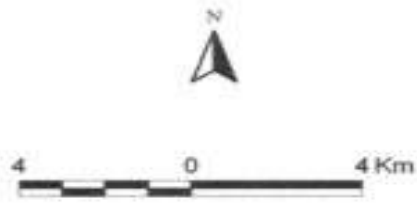

Base Cartográfica: COMEC, 1976

Fonte: COMEC, 2000.

Adaptado por BRASÍLIO (2005) com a utilização do software Flash 5.0 
Apesar de sua extrema importância, Bollmann e Edwiges (2008) mostram que o estado de conservação das águas do rio Belém não está à altura da sua importância simbólica, estando poluídas e contaminadas, primordialmente, por esgotos domésticos e resíduos sólidos. Segundo dados do Instituto Ambiental do Paraná (IAP, 2005), que desde 1992 realiza sistematicamente a avaliação da qualidade das águas em nove pontos amostrais situados na bacia hidrográfica do Rio Belém, o mesmo é classificado como "poluído" a "muito poluído". Atribui-se ainda aos esgotos domésticos (maior parte) e aos efluentes industriais (menor parte) a poluição das águas do rio Belém. (BOLLMANN e EDWIGES, 2008)

De fato, a qualidade da água do rio Belém, por receber resíduos domésticos e resíduos sólidos, permite dizer que esse rio está morto. Essa situação é expressa em diversas pesquisas, como no trabalho de Bollmann e Edwiges (2008).

A pesquisa de Bollmann e Edwiges (2008) foi baseada na coleta de informações sobre a qualidade da água obtida em 23 pontos amostrais (10 pontos no seu canal principal além da foz dos 13 tributários principais) ao longo da bacia do Rio Belém e da aplicação de índices de qualidade de água ( Índice de Qualidade das Águas da National Sanitation Foundation - IQAnsf - e de protocolos perceptivos Indicador de Intensidade Antrópica e Indicador de Valor de Habitat).

O resultado do IQAnsf ${ }^{4}$ mostra que a qualidade da água do Rio Belém piora a partir da sua nascente em direção a sua foz. Conforme mostra o gráfico abaixo, dos 10 pontos avaliados, apenas o primeiro ponto amostral - RB1(localizado no Parque Nascentes do Belém) apresenta boa qualidade da água, os demais pontos analisados mostram uma progressiva piora na qualidade da água culminando com o

\footnotetext{
${ }^{4} \mathrm{O}$ Índice de Qualidade das Águas, elaborado pela National Sanitation Foundation na década de 70 IQAnsf é um número resultante de uma síntese de valores e pesos atribuídos à vários parâmetros físicos, químicos e bacteriológicos, fornecendo uma indicação relativa da qualidade da água e estando baseado em nove parâmetros: temperatura, potencial hidrogeniônico $(\mathrm{pH})$, demanda bioquímica de oxigênio ( $\mathrm{DBO}$ ), nitrogênio total, oxigênio dissolvido, sólidos totais, fósforo total, turbidez, coliformes fecais (termotolerantes). O valor do IQAnsf varia de 1 a 100, avaliando-a desde o ponto de vista de sua tratabilidade para abastecimento e consumo humano. Os valores de 79 a 100 indicam ótima qualidade da água; os valores de 51 a 79 indicam boa qualidade da água; os valores de 36 a 51 indicam qualidade da água aceitável; os valores de 19 a 36 indicam água imprópria para tratamento convencional e os valores de 0 a 19 indicam água imprópria para qualquer tipo de uso. (BOLLMANN e EDWIGES, 2008).
} 
índice de imprópria para todo tipo de uso no curso inferior do rio e em sua foz (RB11). (BOLLMANN e EDWIGES, 2008)

\section{FIGURA 3 - VARIAÇÃO DO IQANSF AO LONGO DO RIO BELÉM - CURITIBA}

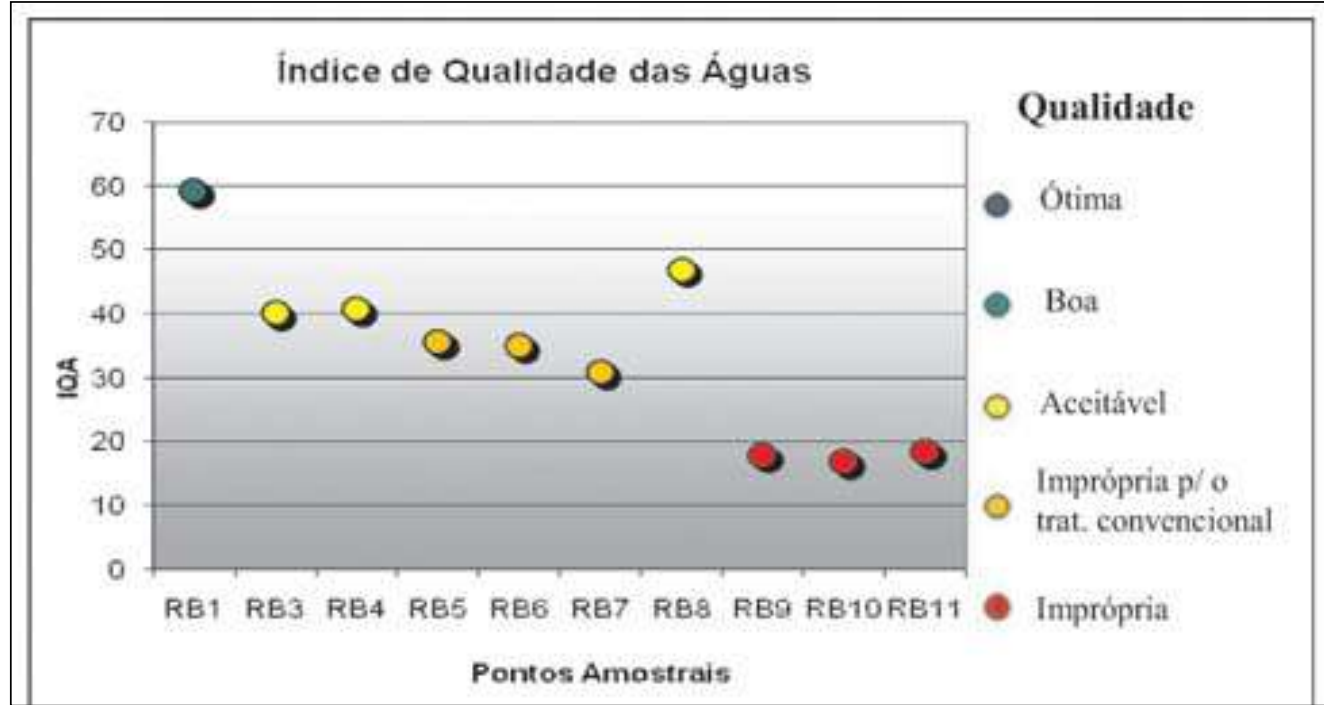

Fonte: BOLLMANN e EDWIGES (2008, p. 450).

Portanto, a pesquisa de Bollmann e Edwiges (2008) afirma os elevados valores de DBO, nitrogênio, fósforo, coliformes fecais, turbidez, e sólidos totais na maior parte do curso do Rio Belém, características típicas de despejos orgânicos comumente lançados em rios urbanos.

De acordo com Brasílio (2005), a cidade de Curitiba apresentou grande crescimento urbano, sobretudo a partir da década de 1970, sendo que os fatores responsáveis por essa intensa urbanização nas últimas décadas foram o êxodo rural e a busca por empregos devido a também crescente industrialização. Mas o aspecto negativo dessa situação se revela na falta de planejamento, que possibilitou a ocupação de áreas ambientalmente mais frágeis, como por exemplo, as margens dos rios. (BRASíLIO, 2005)

Com o rio Belém a situação não foi diferente, pois a ocupação da cidade de Curitiba se fez às suas margens. No entanto, o avanço da urbanização, como aponta Brasílio (2005), acabou substituindo a Floresta Ombrófila Mista de suas margens pela pavimentação de ruas e outras edificações, impermeabilizando a superfície e expondo a cidade a enchentes. 
Dessa forma, foi justamente para controlar a vazão das águas do Rio Belém que foi criado o Passeio Público no ano de 1886, sendo este o primeiro parque urbano da cidade de Curitiba. (DUARTE, 2006)

Duarte (2006) associa a criação do referido parque a uma postura urbanística que tinha por objetivo controlar os rios urbanos com a criação de parques, ao mesmo tempo em que permitia conter as doenças transmissíveis e também abrir territórios para a urbanização.

Contudo, a crescente edificação às margens do Rio Belém, área originalmente destinada a ocupação do rio nos períodos de transbordamento, agravou o problema dos alagamentos anuais, situação que se agravava com o fato do rio ser usado para o esgotamento sanitário. (DUARTE, 2006)

Dessa forma, foram esses os fatores que levaram a canalização do rio Belém em 1977, o que resolveu o problema dos alagamentos, porém não a questão do lançamento de esgoto, como mostra Duarte (2006, p.112): "esconde-se o problema na região central para que ele emerja algumas quadras depois, em um rio sobrecarregado pelas ligações clandestinas de esgoto, em um rio morto."

Em sua pesquisa, Brasílio (2005) analisou o percurso do Belém, constatando que não existe nenhum trecho do rio que esteja de acordo com a legislação ambiental. Dentre os problemas apresentados pelo autor podemos destacar a ocupação das encostas por residências, prédios e indústrias, a inexistência de mata ciliar e a deficiência de saneamento em muitos bairros da bacia.

Brasílio (2005) destaca ainda que, o número de indústrias instaladas às margens do Belém não aumentou, pois a Cidade Industrial, na porção oeste do município de Curitiba e demais municípios vizinhos, absorveram as indústrias que não puderam mais se instalar em Curitiba. Apesar disso, as indústrias que restaram ainda causam muitos problemas, mostrando a ineficiência dos órgãos ambientais em relação a soluções para o meio ambiente.

Como se pode constatar, o rio Belém nasce na porção norte de Curitiba e deságua no rio Iguaçu depois de receber os dejetos da área de maior densidade populacional da cidade. "Ao se juntarem as águas do esgoto doméstico, com as águas dos dejetos industriais, o rio "morreu" e se transformou, apenas, em um emissário de esgoto" (BRASíLIO, 2005, p. 49). 
Para contornar esse problema, uma das medidas tomadas foi a criação do Parque Nascentes do Belém.

\section{AVALIAÇÃO DAS CONDIÇÕES DO PARQUE NASCENTES DO BELÉM}

O Parque Nascentes do Belém está localizado no Bairro Cachoeira em Curitiba, como pode ser observado na figura 4.

Segundo a Prefeitura Municipal de Curitiba, esse parque foi criado com a finalidade de preservar a nascente do referido rio, além de promover a educação ambiental da população. De acordo com a Secretaria Municipal do Meio Ambiente:

No local encontra-se o Centro de Referência das Águas, espaço próprio e equipado para atividades de Educação Ambiental, passando a ser referência nas atividades desenvolvidas pelo Programa Olho D'água, que monitora a qualidade da água dos rios curitibanos (Secretaria Municipal do Meio Ambiente - LUTERO, 2011).

Segundo informações oficiais divulgadas pela Prefeitura Municipal em seu site (SMMA, 2011), o parque, com área de $11.178 \mathrm{~m}^{2}$, conta com diversos equipamentos, como: marco, unidade de Educação Ambiental, sede de manutenção, sanitários, mirante, ponte, fonte, lago, estar/pergolado, caminhos e posto da Guarda Municipal.

Porém, ao realizar uma visita técnica ao local constatou-se uma realidade diferente da idealizada no projeto, pois a construção que deveria ser destinada à Educação Ambiental, está sendo utilizada a aproximadamente cinco anos para a Fundação de Ação Social (FAS) do município que atende a população carente do entorno. Ao coletar informações com uma funcionária do parque a respeito do trabalho de educação ambiental desenvolvido ali, a mesma informou não saber do que se tratava, que apenas a Secretaria Municipal do Meio Ambiente (SMMA) teria tal informação e que nunca teria visto qualquer trabalho nesse sentido na sede. Além disso, não se observou a existência de funcionários da SMMA, apenas um funcionário responsável pela manutenção do local. 


\section{FIGURA 4 - BAIRRO CACHOEIRA EM CURITIBA E A LOCALIZAÇÃO DO PARQUE MUNICIPAL NASCENTES DO BELÉM}

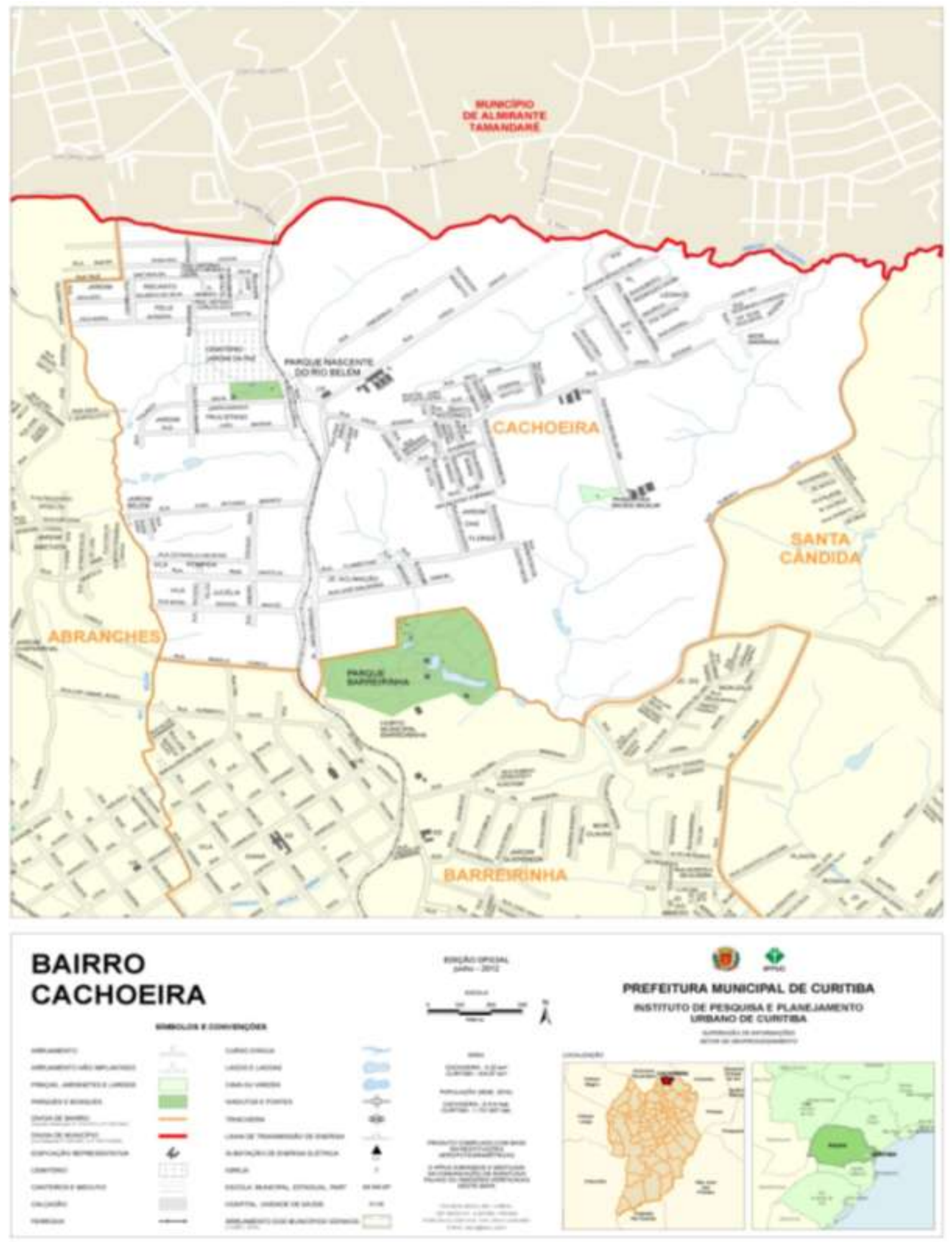

Fonte: IPPUC, 2012 
Em contato telefônico com empregados do parque e da SMMA, constatou-se que ninguém tem informações concretas a respeito desse espaço. Ninguém soube informar como poderia ser agendada uma visita com alunos de escolas da rede estadual e nem tampouco quem seria o responsável pelo monitoramento dessa visita. Essas informações destoam da propaganda oficial, que afirma que o Parque das Nascentes do Belém está devidamente equipado e que conta com funcionários capacitados e que estão trabalhando com projetos de educação ambiental, com ênfase na proteção dos recursos hídricos, nesse espaço.

Diante dessas informações, pode-se identificar certa deficiência dessa unidade de conservação, no que se refere à aplicabilidade de programas de educação ambiental.

Uma possível explicação para essa situação pode ser 0 fato de que o município de Curitiba conta com inúmeras áreas verdes, parques, praças e bosques, gerando certa dificuldade para a administração municipal em equipar devidamente todas essas áreas, adequando-as para o desenvolvimento de projetos ambientais.

A criação de unidades de conservação é uma importante ferramenta na proteção dos recursos hídricos, mas a criação indiscriminada dessas unidades, sem o acompanhamento de uma política efetiva de administração por parte dos órgãos ambientais competentes, compromete seriamente $\mathrm{o}$ alcance de tal política. Infelizmente, essa é a situação do Parque Nascentes do Belém, que além de sofrer problemas estruturais importantes, como a presença de um cemitério na vertente oposta ao parque, conforme mostra a imagem abaixo e também pode ser observado no mapa do bairro (figura 5), não desenvolve nenhum programa voltado à conscientização da população sobre a importância da preservação dos recursos hídricos e do próprio rio Belém, importante símbolo da cidade de Curitiba, conhecida como Capital Ecológica. 


\section{FIGURA 5 - VISTA DO PARQUE MUNICIPAL NASCENTES DO BELÉM E DO CEMITÉRIO JARDIM DA PAZ NO BAIRRO CACHOEIRA - CURITIBA}

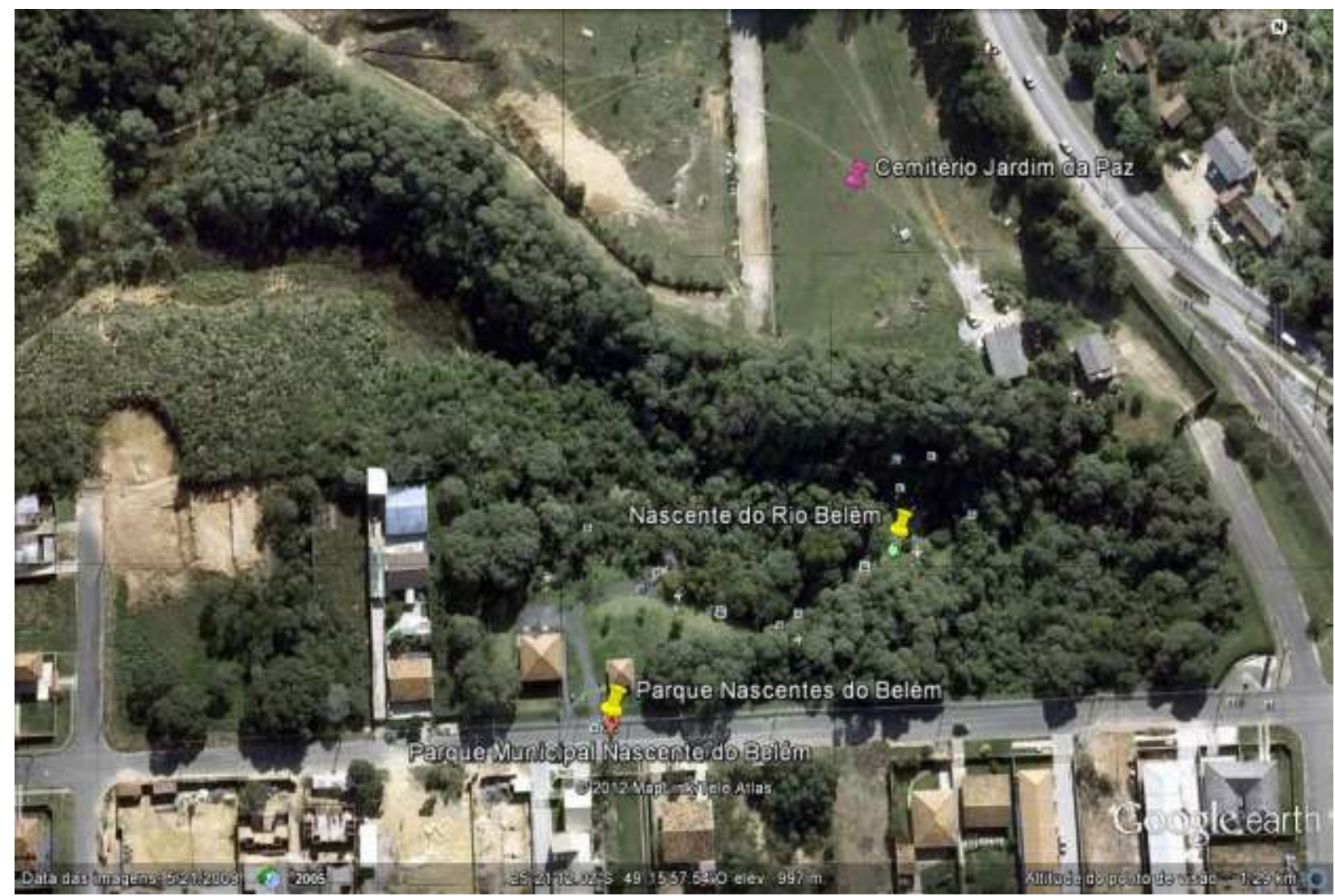

Fonte: Google Earth. Imagem de 2009. Acesso: outubro de 2012.

Ressalta-se que o Cemitério Jardim da Paz já existia antes da criação da referida área de proteção a nascente do Rio Belém. Essa situação releva a incoerência da administração municipal, uma vez que, de nada adianta a criação do parque se a nascente não for realmente protegida através de instrumentos que impeçam sua contaminação por diferentes dejetos.

Em relação aos cemitérios, essa situação poderá acarretar, caso os devidos cuidados não sejam tomados, em contaminação dos recursos hídricos por necrochorume.

Segundo Anjos (2007) a maior parte da população brasileira desconhece a influência ambiental dos cemitérios, a maioria não sabe que a decomposição de um cadáver dá origem ao necrochorume, um "composto viscoso eliminado durante o primeiro ano após o sepultamento, de cor acinzentada, formado por $60 \%$ de água, $30 \%$ de sais minerais e $10 \%$ de substâncias orgânicas, sendo duas delas altamente tóxicas: a putrescina e a cadaverina". Por ser facilmente dissolvido em água, esse 
líquido representa, como apontado pela autora, um meio ideal para a proliferação de doenças infecto-contagiosas.

Desse modo, para que não ocorra a contaminação dos mananciais de abastecimento com conseqüências nocivas a população, a localização, a implantação e operação de cemitérios deve ser acompanhada de perto pelo poder público, de modo a evitar tais problemas. (ANJOS, 2007)

No entanto, apesar do grave problema que os cemitérios podem representar, pouco tem sido feito para amenizar seus impactos. A presença de tal estrutura ao lado de uma área de proteção a nascentes coloca em evidência a incoerência e a incapacidade que o poder público, quer seja municipal, estadual ou federal, tem em gerenciar políticas de proteção ambiental. Assim, políticas e programas de proteção ambiental, na maioria das vezes, constituem apenas discursos políticos, uma vez que não se sustentam na prática.

Portanto, fica claro que os programas de educação e proteção ambiental nem sempre são aplicados corretamente, interesses políticos, como mudanças de partido político na direção de diversas instâncias do poder público, comprometem e mesmo interrompem a execução de programas criados numa gestão anterior. Projetos relevantes para a população acabam extintos ou esvaziados de recursos, passando a existir somente no papel.

A propaganda oficial da prefeitura de Curitiba, promovida por meio de sites oficiais, aponta a importância dos programas de educação ambiental desenvolvidos no Parque Nascentes do Belém, destacando-se a presença do Programa Olho D’Água, criado em 1997 com o objetivo de sensibilizar e despertar a população a um envolvimento para a melhoria da qualidade dos rios em Curitiba.

A preocupação de Curitiba na preservação de seus recursos hídricos refletiu-se emblematicamente na inauguração deste parque, justamente no Dia do Rio, a 24 de novembro de 2001. A área abriga o nascedouro do Belém, rio que começa e termina dentro dos limites do município, cortando a cidade de um extremo ao outro. Pela sua importância como patrimônio natural e histórico da cidade, o Rio Belém é alvo prioritário da meta de revitalização dos rios da capital paranaense. Assim, a implantação do parque teve como objetivo a proteção ambiental da sua nascente. No local encontra-se o Centro de Referência das Águas, espaço próprio e equipado para atividades de Educação Ambiental, passando a ser referência nas atividades desenvolvidas pelo Programa Olho D'água, que monitora a qualidade da água dos rios curitibanos. (LUTERO, 2011) 
Mas em visita ao parque, percebe-se que a realidade é bem diferente. Não há representantes de órgãos ambientais trabalhando em nenhum projeto ambiental. Em decorrência disso, o parque recebe pouquíssimos visitantes, pois sem a presença de um representante e de programas ambientais que envolvam a população, na prática, pouquíssimo pode ser feito pela proteção dos mananciais da cidade. Prova disso, é que o rio Belém continua contaminado por resíduos diversos em todos os trechos de seu curso, cabendo-lhe, como aponta BRASíLIO (2005), a triste frase: "um rio que já nasce morto".

Portanto, se a criação do Parque das Nascentes tinha como propósito proteger o rio Belém e dar suporte a práticas de educação ambiental voltadas à proteção dos recursos hídricos, o mesmo não tem sido alcançado, dada as muitas fragilidades que essa unidade de conservação apresenta.

\section{CONSIDERAÇÕES FINAIS}

O agravamento da falta de água, que tem se intensificado nos últimos anos, tem levado as pessoas a perceberem que estão cada vez mais próximas de uma crise mundial, pois se no passado a escassez já foi motivo para muitas guerras, a escassez de água pode se tornar a principal causa de um futuro conflito. Desse modo, o controle dos recursos hídricos configura-se, para muitos países, como a questão mais importante neste século. (BARROS e AMIN, 2008)

Diante desse quadro, é necessário adotar uma forma de uso sustentável da água, promovendo a proteção dos mananciais que estão conservados e a recuperação daqueles que já estão prejudicados, caso do rio Belém, em Curitiba.

Mas a realidade é diferente da teoria, o que se constatou através desta análise é que a implantação do Parque Nascentes do Belém não está contribuindo para a proteção ambiental da nascente e o seu propósito de dar suporte para a prática de atividades de educação ambiental não está em andamento. Existe o Programa Olho D’Água, mas a sua efetivação não se faz presente no local, a estrutura está sendo utilizada como uma sede de apoio social à população do entorno, retratando, dessa forma, que o propósito de criação da unidade de conservação não está sendo atendido. 
Assim, a constatação de fragilidades estruturais e administrativas no Parque Nascentes do Belém mostra que é preciso bem mais do que a criação de unidades de conservação, é necessário um verdadeiro comprometimento do poder público com a proteção ambiental, extrapolando interesses eleitoreiros e promovendo eficazmente a proteção e recuperação dos recursos hídricos em nosso país. E, é claro, um maior envolvimento da população, visando à conscientização de que o homem e a natureza podem conviver juntos sem que ocorra a degradação ambiental.

\section{REFERÊNCIAS}

ANJOS, Roberta Maas. Cemitérios: uma ameaça a saúde humana? In: Anais do 24ํㅜㄴ Congresso Brasileiro de Engenharia Sanitária e Ambiental. Belo Horizonte, 2007.

BARROS, Fernanda Gene Nunes; AMIN, Mário M. Água: um bem econômico de valor para o Brasil e o mundo. Revista Brasileira de Gestão e Desenvolvimento Regional, v. 4, n. 1, p. 75-108, Taubaté, 2008.

BOLLMANN, Harry Alberto.: EDWIGES, Thiago. Avaliação da qualidade das águas do Rio Belém, Curitiba-PR, com o emprego de indicadores quantitativos e perceptivos. Eng. Sanit. Ambient. [online]. vol.13, n.4, pp. 443-452. 2008.

BONATTO, Almir. Uma alternativa para o escoamento sanitário em áreas periféricas no município de Curitiba - Paraná. Espaço para a saúde, v.1, n.2, p. 164-195, Londrina, 2000.

\section{BRASIL, Constituição Federal de 1988.}

BRASIL, SNUC, lei nำ 9985/2000.

BRASIL, Estatuto da Cidade, lei no 10.257/2001.

BRASÍLIO, Wilson. Industrialização e degradação ambiental: o caso do Rio Belém, em Curitiba, PR. Dissertação (Mestrado) Universidade Federal do Paraná, Curitiba, 2005. 79 p.

CARVALHO, Osires; RODRIGUES, Flávio. Recursos hídricos e desenvolvimento sustentável (Escala de necessidades humanas e manejo ambiental integrado). GEOgraphia, Ano. 6, n.12, 2004.

CARVALHO, P. F; BRAGA, R. Zoneamento Ambiental Urbano por micro-bacias hidrográficas: Estudo de viabilidade em cidade média no estado de São Paulo - BR. Grupo de Pesquisa Análise e Planejamento Territorial - GPAPT, disponível na Web 
http://www.rc.unesp.br/igce/planejamento/gpapt/Artigos\%20pdf\%20final/pompeu\%20 PDF/Carvalho\%20e\%20Braga\%20Pluris\%202005.pdf. Acesso em: 30/12/2010.

COSTA, Patrícia. Unidades de conservação: matéria-prima do ecoturismo. São Paulo: Aleph, 2002

DUARTE, Fábio. Rastros de um rio urbano - cidade comunicada, cidade percebida. Ambiente e Sociedade, v. 9, n.2, p.105-122, 2006.

FLORIANO, Eduardo Pagel. Planejamento Ambiental. Caderno Didático, n. 6, v.1, 54 p. Santa Rosa, 2004.

IAP. Monitoramento da qualidade das águas na região metropolitana de Curitiba. Instituto Ambiental do Paraná. Curitiba, 1995.

IBGE, Instituto Brasileiro de Geografia e Estatística. Pesquisa Nacional de Saneamento Básico 2008. Rio de Janeiro, 2010. Disponível em: http://www.ibge.gov.br/home/estatistica/populacao/condicaodevida/pnsb2008/PNSB_ 2008.pdf. Acesso: outubro de 2012.

IBGE, Instituto Brasileiro de Geografia e Estatística. Atlas Saneamento 2011. Rio de Janeiro, 2011. Disponível em: http://www.ibge.gov.br/home/presidencia/noticias/noticia_visualiza.php?id_noticia=19 98\&id_pagina=1 Acesso em: outubro de 2012.

LIBÂNIO, Paulo Augusto Cunha. et al. A dimensão da qualidade de água: avaliação da relação entre indicadores sociais, de disponibilidade hídrica, de saneamento e de saúde pública. Engenharia Sanitária e Ambiental, v.10, n.3, Rio de Janeiro, 2005.

LUTERO, Martim. Parque Municipal Nascentes do Belém. Disponível em: http://www.curitiba.pr.gov.br/conteudo/parques-e-bosques-parque-municipalnascentes-do-belem-secretaria-municipal-do-meio-ambiente/314). Acesso em: $12 / 02 / 2011$.

MORAES, Danielle S. de Lima; JORDÃO, Berenice Q. Degradação de recursos hídricos e seus efeitos sobre a saúde humana. Saúde pública, v.36, n.3, São Paulo, jun.2002.

REBOUÇAS, Aldo da C. (Coord.) et al.. Aspectos relevantes do problema da água. In:_ Águas doces no Brasil: capital ecológico, uso e conservação, 2. ed., São Paulo: Escrituras. .2002. p. 687-702

REBOUÇAS, Aldo da C. Água no Brasil: abundância, desperdício e escassez. Bahia Análise \& Dados, Salvador, v. 13, n. ESPECIAL, p. 341-345, 2003.

RYLANDS, Anthony B.; BRANDON, Katrina. Unidades de conservação brasileiras. Megadiversidade, v. 1, n. 1, 2005. 
SÁ -SILVA, Jackson R. et al. Pesquisa documental: pistas teóricas e metodológicas. Revista Brasileira de História \& Ciências Sociais, v. 1, 2009.

SALATI, Angela et al. Temas ambientais relevantes. Estudos Avançados, v.20, n. 56, p.107-127, São Paulo, 2006.

SANTOS JUNIOR, Oswaldo Dias dos. O desenvolvimento do turismo em unidades de conservação: Caracterização do uso público no Parque Estadual da llha do Mel PR. Dissertação de Mestrado. Universidade do Vale do Itajaí. Balneário Comburiu, 2006.

SMMA, Secretaria Municipal do Meio Ambiente, Prefeitura Municipal de Curitiba. Disponível na web: http://www.curitiba.pr.gov.br/conteudo/parques-e-bosquesparque-municipal-nascentes-do-belem-secretaria-municipal-do-meio-ambiente/314. Acesso em: 03/02/2011.

SILVA, Christian L. et al. Plano Diretor de Curitiba como Política Urbana para a preservação dos recursos hídricos: Uma avaliação da sua exeqüibilidade sob a ótica neo-institucionalista. E - revista Unioeste, Vol. 12 no 01, 2008

SILVA, Wilza C. M. Monumento Natural Vale dos Dinossauros: Meio biofísico e interfaces eco-sociais. Universidade Federal da Paraíba, João Pessoa - PB, mar/2004. Disponível na web http://www.biblioteca.sebrae.com.br/bds/BDS.nsf/E 6E3F4E2D5C8464E0 3256F9000534886/\$File/NT000A3472.pdf. Acesso em: 23/12/2010.

TUNDISI, José G. Recursos hídricos. Parcerias Estratégicas, n.20, jun.2005.

UICN. União Internacional de Conservação da Natureza, 1994. Disponível em: http://www.repsol.com/br_pt/corporacion/responsabilidadcorporativa/biodiversidad/nu estra-estrategia/que-es-biodiversidad/union-intenacional-conservacionnaturaleza/default.aspx. Acesso em:13/01/2011.

(Recebido em: 10/10/2011. Aceito em 30/11/2012). 